\title{
Ilgın (Konya) Yerleşim Alanı Zeminlerinin Taşıma Gücü Özellikleri
}

${ }^{* 1}$ M. Tahir Nalbantçılar, ${ }^{2}$ Turgay Beyaz ve ${ }^{3}$ Nagihan Özlen

${ }^{1}$ Mühendislik ve Doğa Bilimleri Fakültesi, Jeoloji Mühendisliği Bölümü Konya Teknik Üniversitesi, Konya, Türkiye

${ }^{2}$ Mühendislik Fakültesi, Jeoloji Mühendisliği Bölümü Pamukkale Üniversitesi, Denizli, Türkiye

${ }^{3}$ Fen Bilimleri Enstitüsü, Jeoloji Mühendisliği Anabilim Dalı, Konya Teknik Üniversitesi, Konya, Türkiye

\section{Özet}

Ilgın (Konya) yerleşim alanında temel kayalar üzerine uyumsuzlukla gelmiş kohezyonlu ve kohezyonsuz özellikli zeminler bulunmaktadır. 1. Derece deprem bölgesinde bulunan Ilgın için depremsellik en önemli tehditlerdendir. Bu çalışmada zeminin taşıma gücünü belirlemek için örnekleme amacıyla, farklı noktalarda 4 adet sondaj kuyusu ve 7 adet araştırma çukuru açılmıştır. Alınan UD numuneleri üzerinde deneyler yapılmıştır. Buna göre zeminlerin çakıllı siltli kum, kumlu siltli kil, siltli kum, siltli killi kum, killi silt ve siltli kil'den oluştuğu belirlenmiştir. Yine bu zeminlerin kesme dayanımı, kohezyonu, içsel sürtünme açısı ile taşıma gücü değerleri hesaplanmıştır. Elde edilen değerlere bağlı olarak yapıların planlanması gerekmektedir. Ayrıca, olası deprem hasarlarını en aza indirgeyecek şekilde mevcut yapıların statik durumlarında iyileştirmelerin yapılması gerekmektedir.

Anahtar kelimeler: Jeoteknik, Zemin, Taşıma gücü, Ilgın, Türkiye

\section{Bearing Capacity Characteristics of the Soils of the Ilgın (Konya) Settlement Area}

\begin{abstract}
In Ilgin (Konya) settlement area, there are cohesion and non-cohesion soils that are unconformably overlain on the basement rocks. Seismicity is one of the most important threats for Ilgin located in the first degree seismic zone. In this study, 4 boreholes and 7 research pits were drilled at different points in order to determine the carrying capacity of the soil. Experiments were performed on the samples taken. Accordingly, it was determined that the soils consist of gravelly silty sand, sandy silty clay, silty sand, silty clay sand, clayey silt and silty clay. Shear strength, cohesion, internal friction angle and bearing strength values of these soils were also calculated. Structures should be planned depending on the values obtained. In addition, improvements to the static conditions of existing structures should be made to minimize possible earthquake damage.
\end{abstract}

Key words: Geotechnics, Soil, Bearing capacity, Ilgın, Turkey

\footnotetext{
*Sorumlu yazar: Adres: Mühendislik ve Doğa Bilimleri Fakültesi, Jeoloji Mühendisliği Bölümü Konya Teknik Üniversitesi, Konya TÜRKIYE. E-posta adresi: mtnalbantcilar@ktun.edu.tr
} 


\section{Giriş}

Tüm dünyada yerleşim alanlarının planlanmasında, zemin özellikleri açısından güvenli veya riskli olan bölgelerin tespit edilmesinin gerekliliği, özellikle deprem, heyelan v.b. doğal afetler gözönüne alındığında oldukça önem teşkil etmektedir. Ülkemiz gerek jeolojik özellikleri nedeniyle birçok doğal afet ile yüz yüzedir. Özellikle 1999 y1lında meydana gelen Marmara Depreminden sonra yapılaşma öncesinde zemin analizlerinin yapıldığı, ağırlıklı olarak yerel ölçekli mühendislik çalışmalarının önemi ve gerekliliği birkez daha ortaya çıkmıştır.

Yerleşim alanlarında meydana gelebilecek deprem gibi bir doğal afetin oluşturacağı etkileri önceden tahmin edebilmek veya oluşabilecek zararları en aza indirebilmek, o bölgenin jeolojik ve tektonik özelliklerini iyi tanımlamaktan geçmektedir. $\mathrm{Bu}$ da yapılaşma öncesinde, zeminin mühendislik özelliklerinin yanı sıra, olası tehlike ve risklerinin analiz edilmesiyle sağlanabilir. $\mathrm{Bu}$ amaçla yapılan çalışmalar, kentte uygulanacak imar planlarının önemli bir altlı̆̆ını da oluşturmaktadır. Bu çalışmada Ilgın'ın hızla gelişen kentleşme sürecine rehber olması maksadıyla zeminin taşıma gücü özelliklerinin belirlenmesi hedeflenmiştir.

Ilgın (Konya) ilçe merkezi yerleşim alanının 1. Derece deprem bölgesinde yer alması, gelişmekte olan yapılaşmanın önünde önemli bir risk faktörü oluşturmakta, zeminin alüvyondan oluşması, sismik etkilerin sebep olduğu farklı problemler ile karşılaşılmasına neden olmaktadır. Bunların yanısıra yeraltısu seviyesinin de yüzeye yakın olması zemin dayanımını oldukça düşürmektedir. $\mathrm{Bu}$ çalışma kapsamında, Ilgın (Konya) yerleşim alanındaki zeminlerin kesme dayanımları belirlenerek elde edilen veriler ile taşıma gücü değerleri hesaplanmıştır.

\section{1. Çalışma Alanının Tanıtılması}

Çalışma alanı 1/100.000 ölçekli ILGIN-L27 paftasında, Konya’nın 90 km kuzeybatısındaki Ilgın ilçesinin yerleşim alanı ve yakın çevresini kapsamakta olup, yaklaşı $40.00 \mathrm{~km}^{2}$ 'lik bir alandır (Şekil 1). 


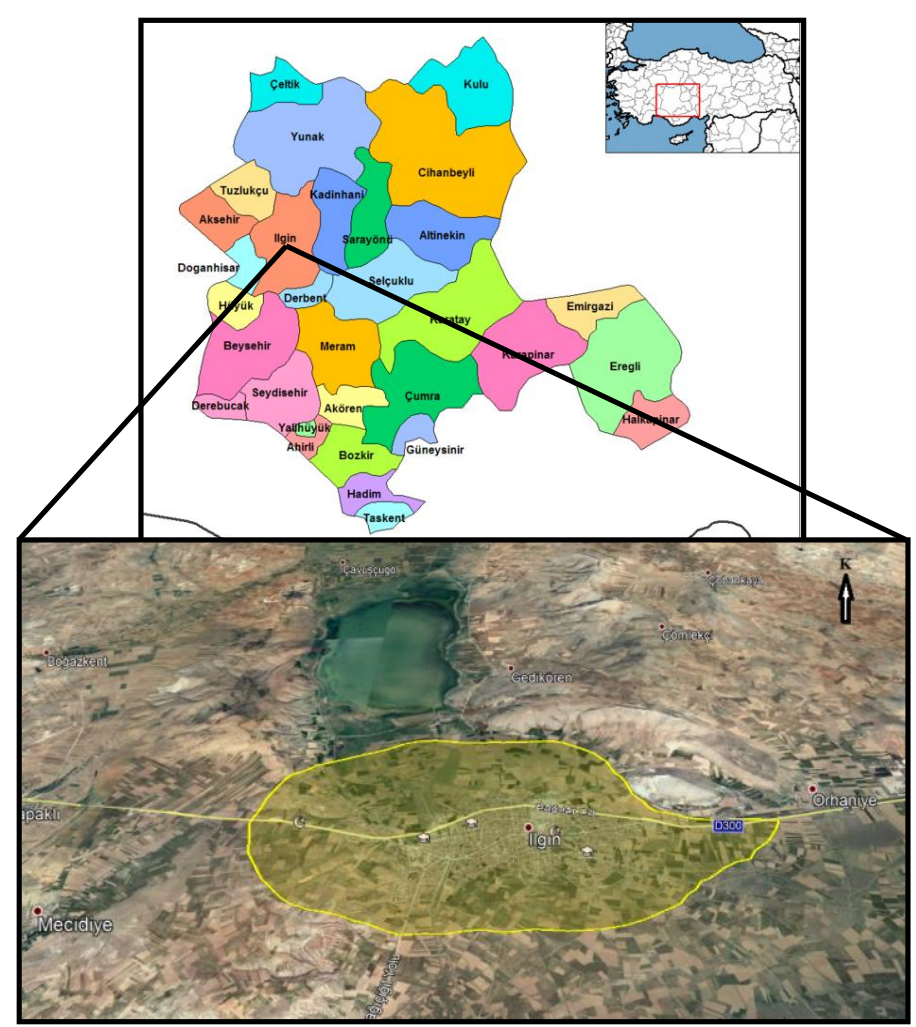

Şekil 1. İnceleme alanının yer bulduru haritası [1]

\section{Materyal ve Metot}

$\mathrm{Bu}$ araştırmada önceki çalışmalarda elde edilen veriler ışı̆̆ında arazide yapılan inceleme, ölçüm ve gözlemlerle zeminin özellikleri ortaya konmaya çalışılmıştır.

Ilgın (Konya) yerleşim alanındaki zeminlerin özelliklerinin belirlenmesi amacıyla sondaj ve araştırma çukurları ile numuneler alınarak, Ankara Üniversitesi Yerbilimleri Uygulama ve Araştırma Merkezi'nin (YEBİM) laboratuvarında Elek Analizi, Hidrometre ve Direk Kesme deneyleri yapılmıştır. Yerleşim alanında yeraltı su seviyesi de yerinde ölçümlerle belirlenmiştir.

Deneyler sonucunda elde edilen veriler yorumlanarak, inceleme alanındaki zeminlerin jeoteknik özellikleri belirlenerek, gerekli önlemler ortaya konulmuştur.

\subsection{Jeoloji}

İnceleme alanı birçok araştırmacı tarafindan çalışılmıştır [2-10]. MTA tarafindan yapılan harita çalışmasında inceleme alanı yer almaktadır [11] (Şekil 2). 

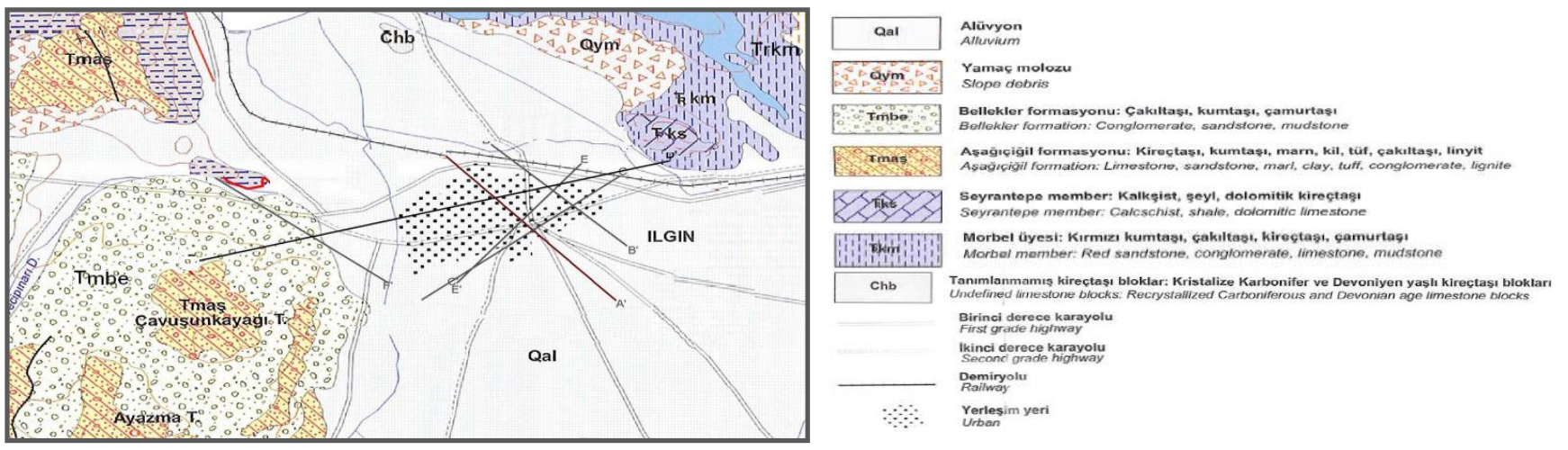

Şekil 2. İnceleme Alanı ve Çevresine ait Jeoloji Haritası [11]

Bu çalışmaya göre istif alttan üste doğru; Karbonifer yaşlı, silttaşı, şeyl, kireçtaşı, çakıltaşı, çört ardalanmalı matriks içerisinde yer alan kireçtaşı blokları ve bazı volkanik kayalardan oluşan Halıcı formasyonu temeli oluşturur. Bölgede Halıcı formasyonu; gri, siyah ve beyaz renkli ortakalın katmanlı kireçtaşı ve dolomit yapılı Kurşunlu kireçtaşı üyesi ve muhtemelen Erken Paleozoyik yaşı Tanımlanmamış kireçtaşı bloklarından oluşur [4]. Halıcı formasyonu üzerinde kırmızı renkli kırıntılılar (Morbel üyesi) ile çoğunlukla oolitik kireçtaşlarından (Seyrantepe üyesi) oluşan Triyas yaşlı Katarası formasyonu açısal uyumsuz olarak yer alır. Temel birimler üzerine Alt-Orta Miyosen yaşlı, kireçtaşı, çakıltaşı, kumtaşı, silttaşı, marn, kiltaşı, çamurtaşı, tüf ve yer yer organik boyamalı killer ile ince merceksel linyit damarlarından oluşan Aşağıçiğil formasyonu gelmektedir. Kumtaşı, çakıltaşı, çamurtaşı ve yer yer linyitli seviyelerden oluşan Bellekler formasyonu örter. Tüm birimleri uyumsuz olarak örten Kuvaterner oluşumu Alüvyondan oluşur.

\subsection{Depremsellik}

Ülkemizdeki yapı kalitesi itibariyle yıkıcı deprem eşiğinin $M=5.0$ olduğu kabulüyle, çalışma alanı ve çevresinde orta büyülükte deprem meydana gelmektedir. Bugüne kadar ölçülebilmiş Ms $\geq 5.0$ magnitüd aralığındaki depremlerin sayısı 14 adettir (Şekil 3). Bunun yanında $6.0 \leq \mathrm{Ms} \leq 6.5$ magnitüd aralığındaki yıkım etkisi çok fazla olan depremlerin 1 adet olduğu görülmektedir.

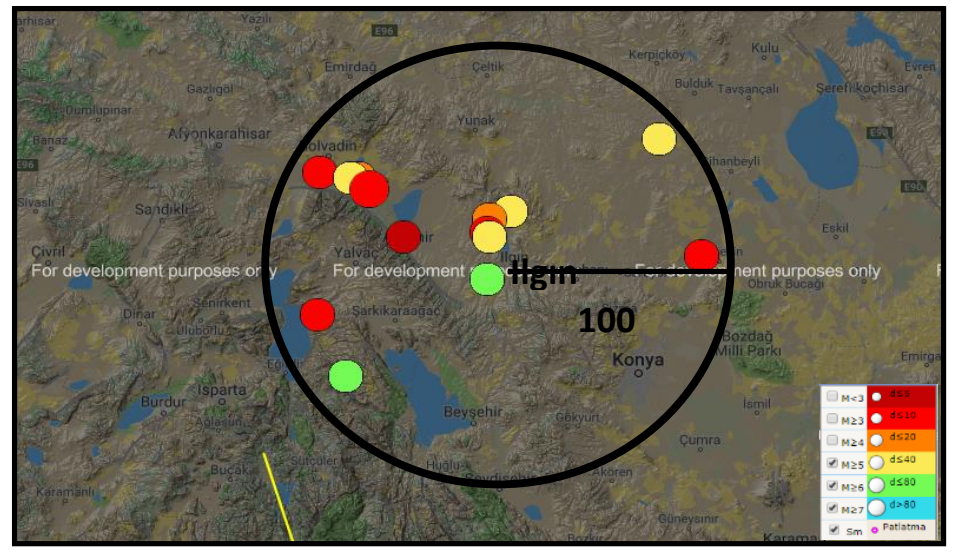

Şekil 3. Ilgın (Konya) ilçesi ve $100 \mathrm{~km}$ yarıçapındaki bölgede 5 ve üzerinde olan depremler [12] 


\section{Jeoteknik İncelemeler}

İnceleme alanında arazi çalışmaları kapsamında toplam derinliği $32.50 \mathrm{~m}$ olan yedi adet araştırma çukuru ve toplam derinliği $37.50 \mathrm{~m}$ olan dört adet sondaj kuyusu açılmıştır. Araziden Torba ve UD numuneleri alınmış ve Ankara Üniversitesi YEBİM laboratuvarlarında deneylere tabi tutulmuşlardır. İnceleme alanından alınan Torba ve UD numuneleri üzerinde elek analizi deneyi yapılmıştır. Şekil 4'da SK-1 numunesinin elek analizi sonuçlarına ait tane boyu dağı̆lım grafiği verilmiştir.

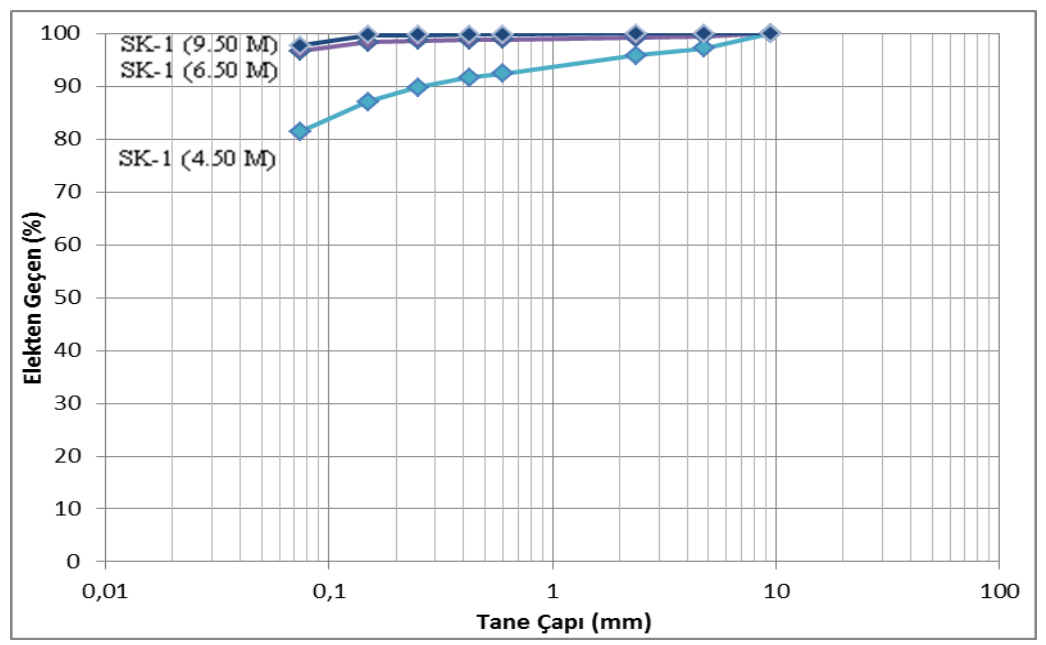

Şekil 4. SK-1 numunesinin elek analizi sonuçlarına göre Tane Boyu Dağılım grafiği

Tüm numunelerin elek analizi deneyi sonucunda zeminin inceleme alanında çakıllı siltli kum, kumlu siltli kil, siltli kum, siltli killi kum, killi silt ve siltli kil'den oluştuğu belirlenmişsir (Çizelge 1).

Çizelge 1. Numuneler üzerinde yapılan deney sonuçları

\begin{tabular}{|c|c|c|c|c|c|c|c|c|c|c|c|}
\hline \multirow[b]{2}{*}{ Numune Ad 1} & \multirow[b]{2}{*}{$\begin{array}{l}\text { Derinlik } \\
\text { (m) }\end{array}$} & \multicolumn{2}{|c|}{ Elek Analizi (\%) } & \multicolumn{3}{|c|}{$\begin{array}{c}\text { Atterberg } \\
\text { Limitleri }(\%)\end{array}$} & \multirow{2}{*}{$\begin{array}{c}\text { Zemin } \\
\text { Sinifi } \\
\text { (USCS) }\end{array}$} & \multirow{2}{*}{$\begin{array}{l}\text { Özgül } \\
\text { Ağırlık } \\
\left(\mathrm{g} / \mathrm{cm}^{3}\right)\end{array}$} & \multirow[b]{2}{*}{$\begin{array}{c}\text { Yoğunluk } \\
\left(\mathrm{g} / \mathrm{cm}^{3}\right)\end{array}$} & \multirow{2}{*}{$\begin{array}{c}\text { Doğal } \\
\text { Su } \\
\text { İçeriğ } \\
(\%)\end{array}$} & \multirow{2}{*}{$\begin{array}{c}\text { Doğal } \\
\text { Birim } \\
\text { Hacim } \\
\text { Ağırlık } \\
\left(\mathrm{kN} / \mathrm{m}^{3}\right)\end{array}$} \\
\hline & & $\begin{array}{l}4 \text { Nolu } \\
\text { Elek } \\
\text { Kalan }\end{array}$ & $\begin{array}{c}200 \\
\text { Nolu } \\
\text { Elek } \\
\text { Geçen }\end{array}$ & LL & PL & PI & & & & & \\
\hline AÇ-1(TORBA) & 4,50 & 0,3 & 59,7 & 40 & 20 & 20 & CL & - & - & 18 & - \\
\hline AÇ-1(TORBA) & 6,00 & 0,1 & 88,4 & 43 & 21 & 23 & CL & - & - & 23 & - \\
\hline AÇ-2(TORBA) & 5,00 & 0 & 79,5 & 36 & 19 & 17 & $\mathrm{CL}$ & - & - & 18 & - \\
\hline AÇ-3(TORBA) & 4,00 & 0 & 87,5 & 32 & 19 & 13 & $\mathrm{CL}$ & - & - & 20 & - \\
\hline AÇ-4(TORBA) & 4,00 & 0,4 & 70,06 & 41 & 23 & 18 & $\mathrm{CL}$ & - & - & 26 & - \\
\hline AÇ-5(TORBA) & 4,50 & 0 & 86,5 & 37 & 23 & 14 & CL & - & - & 8 & - \\
\hline AÇ-6(TORBA) & 6,00 & 0 & 65,4 & \multicolumn{3}{|c|}{$*$} & ML & - & - & 13 & - \\
\hline AÇ-7(TORBA) & 3,00 & 0 & 75,4 & \multicolumn{3}{|c|}{$*$} & ML & - & - & 16 & - \\
\hline SK-1(UD-1) & 4,50 & 5 & 67,1 & 37 & 23 & 14 & $\mathrm{CL}$ & 2,72 & 1,90 & 17 & 18,59 \\
\hline SK-1(UD-2) & 6,50 & 0,9 & 93,5 & 50 & 20 & 30 & $\mathrm{CH}$ & 2,78 & 1,92 & 20 & 18,83 \\
\hline SK-1(UD-3) & 9,50 & 0 & 95,7 & 30 & 20 & 19 & $\mathrm{CL}$ & 2,76 & 1,97 & 26 & 19,37 \\
\hline SK-2(UD-1) & 3,00 & 0 & 88,2 & 36 & 19 & 17 & $\mathrm{CL}$ & 2,75 & 1,99 & 18 & 19,56 \\
\hline SK-2(UD-2) & 6,00 & 6,8 & 53,6 & \multicolumn{3}{|c|}{$*$} & ML & 2,70 & - & 10 & - \\
\hline SK-2(UD-3) & 8,00 & 16,7 & 22,3 & \multicolumn{3}{|c|}{$*$} & SM & 2,78 & 1,94 & 14 & 19,00 \\
\hline SK-2(UD-4) & 10,00 & 4,3 & 81,2 & 35 & 18 & 17 & $\mathrm{CL}$ & 2,73 & 1.95 & 24 & 19,14 \\
\hline
\end{tabular}




\begin{tabular}{|c|c|c|c|c|c|c|c|c|c|c|c|}
\hline SK-2(UD-5) & 12,00 & 7,1 & 11,7 & \multicolumn{3}{|c|}{$*$} & SM & 2,81 & - & 24 & - \\
\hline SK-3(UD-1) & 3,00 & 0 & 85,5 & \multicolumn{3}{|c|}{ * } & ML & 1,47 & 2,03 & 24 & 19,93 \\
\hline SK-3(UD-2) & 6,00 & 2,7 & 92,9 & 39 & 21 & 18 & $\mathrm{CL}$ & 2,82 & 2,12 & 22 & 20,81 \\
\hline SK-3(UD-3) & 8,00 & 1,5 & 93,9 & 44 & 25 & 19 & $\mathrm{CL}$ & 2,83 & 2,00 & 30 & 19,58 \\
\hline SK-3(UD-4) & 10,00 & 0 & 96,1 & 55 & 31 & 24 & $\mathrm{MH}$ & 2,78 & 1,83 & 27 & 17,96 \\
\hline SK-4(UD-1) & 3,00 & 0,9 & 68,6 & \multicolumn{3}{|c|}{ * } & ML & 2,75 & - & 31 & - \\
\hline SK-4(UD-2) & 4,50 & 0 & 88,9 & \multicolumn{3}{|c|}{ * } & ML & 2,78 & 1.87 & 21 & 18,34 \\
\hline SK-4(UD-3) & 6,00 & 0 & 94 & 39 & 21 & 18 & $\mathrm{CL}$ & 2,80 & 2.01 & 25 & 19,76 \\
\hline SK-4(SPT-1) & 6.25 & 0,2 & 87,2 & \multicolumn{3}{|c|}{$*$} & ML & 2,73 & - & 27 & - \\
\hline
\end{tabular}

* Numunenin kum ve silt miktarı fazla olduğundan Atterberg Limitleri hesaplanamamıştır.

Altı adet zemin numunesi üzerinde farklı yüklemeler yapılarak zeminin kesme dayanımları belirlenmiştir (Şekil 5).

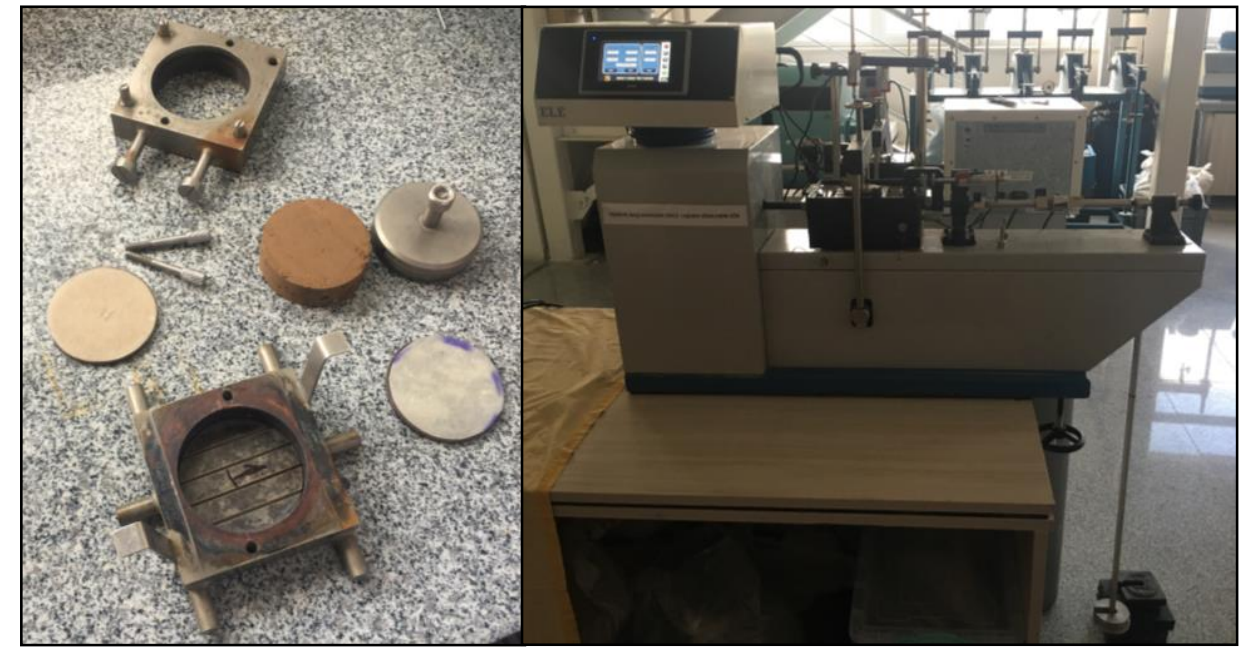

Şekil 5. Direk Kesme Deney Düzeneği

SK-1 sondajına $(6.50 \mathrm{~m})$ ait UD numunesine $12.5,25,50,100 \mathrm{kPa}$ yüklemeleri yapılmış ve numunede oluşan deformasyonlar belirlenmiştir. Elde edilen veriler 1şığında kayma gerilmesinormal gerilme grafiği çizilmiş, kohezyon ve içsel sürtünme açısı belirlenmiştir (Şekil 6).

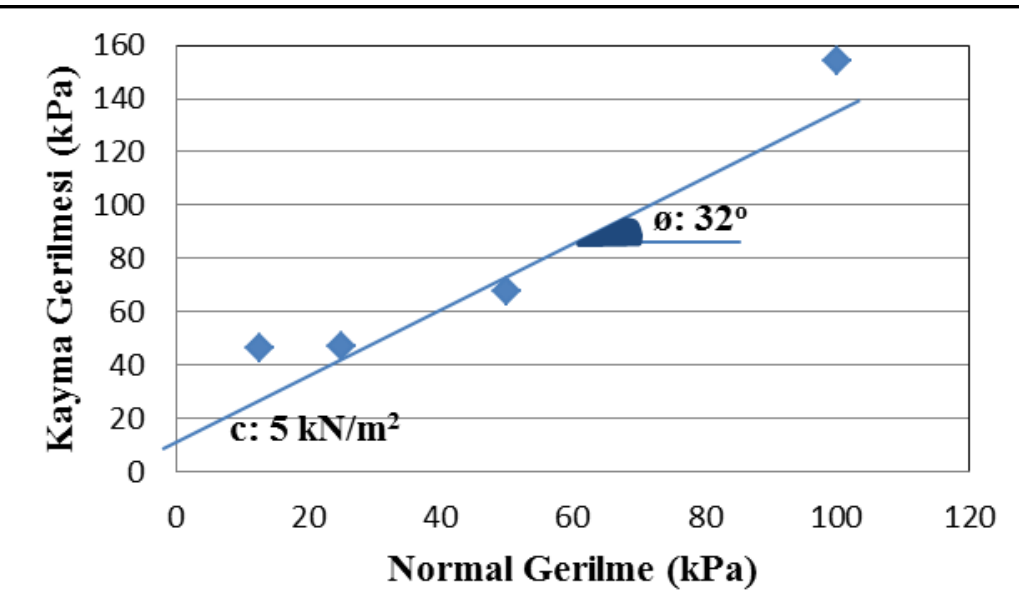

Şekil 6. Kayma gerilmesi-Normal gerilme grafiği 
Terzaghi bağıntısı [13] kullanılarak kohezyonlu zeminlerde kare temel için taşıma gücü ile emniyetli taşıma gücünü; 1.1 ve 1.2 eşitlikleri ile hesaplamışlardır.

$$
\begin{aligned}
& \mathrm{q}_{\mathrm{f}}=(1+0.3 \mathrm{~B} / \mathrm{L}) \cdot \mathrm{c} \cdot \mathrm{N}_{\mathrm{c}}+\gamma_{1} \cdot \mathrm{D}_{\mathrm{f}} \cdot \mathrm{N}_{\mathrm{q}}+0.5(1-0.2 \mathrm{~B} / \mathrm{L}) \gamma_{2} \cdot \mathrm{B} \cdot \mathrm{N}_{\gamma} \\
& \mathrm{q}_{\mathrm{e} m n}=\mathrm{q}_{\mathrm{f}} / \mathrm{SF}
\end{aligned}
$$

qf: Taşıma gücü $\left(\mathrm{kg} / \mathrm{cm}^{2}\right)$, qemn: Emniyetli taşıma gücü $\left(\mathrm{kg} / \mathrm{cm}^{2}\right)$, c: Kohezyon $\left(\mathrm{kN} / \mathrm{m}^{2}\right), \mathrm{D}_{\mathrm{f}}$ : Temel derinliği (m), B: Temel genişliği (m), L: Temel uzunluğu $(\mathrm{m}), \gamma_{1}$ : Temel üstünde yer alan zeminin birim ağırlığ $\left(\mathrm{kN} / \mathrm{m}^{3}\right), \gamma_{2}$ : Temel zeminin birim ağırlığ1 $\left(\mathrm{kN} / \mathrm{m}^{3}\right), \mathrm{SF}$ : Emniyet katsayıs1, $\varphi=32^{\circ}, \mathrm{Nc}=35.5, \mathrm{Nq}=23.2$ ve $\mathrm{N} \gamma=24.90$ alınmıştır. Kare temel için elde edilen değerlere göre inceleme alanında yer alan zeminin emniyetli taşıma gücü yaklaşı $0.86 \mathrm{~kg} / \mathrm{cm}^{2}$ bulunmuştur.

\section{Sonuçlar}

İnceleme alanında yapılan çalışmalar sonucunda, zeminin çakıllı siltli kum, kumlu siltli kil, siltli kum, siltli killi kum, killi silt ve siltli kil olduğu ve Direk Kesme deneyleri sonucunda kohezyon (c) $5 \mathrm{kN} / \mathrm{m}^{2}$, içsel sürtünme açısının $(\varphi) 32^{\circ}$ olduğu belirlenmiştir. Ayrıca inşaat alanında kare temel olabileceği dikkate alındığında emniyetli taşıma gücü $0.86 \mathrm{~kg} / \mathrm{cm}^{2}$ hesaplanmıştır.

Ms $\geq 5.0$ magnitüd aralığında 14 ve $6.0 \leq \mathrm{Ms} \leq 6.5$ magnitüd aralığında 1 adet depremin olmuş olması; Ilgın'daki yapılaşmaların mutlaka "Deprem Bölgelerinde Yapılacak Binalar Hakkındaki Yönetmelik” hükümlerine uygun olarak yapılması gerekmektedir.

Ilgın'da bu çalışmayla elde edilen jeoteknik verilere göre yapılaşmanın planlanması gerekmektedir. Ayrıca olası depremin oluşturabileceği hasarları en aza indirgeyecek şekilde mevcut yapılarda iyileştirmelerin yapılması gerekmektedir.

\section{Teşekkür}

$\mathrm{Bu}$ araştırma; Konya Teknik Üniversitesi Bilimsel Araştırmalar Koordinatörlüğü’nün KTUN BAP-191007016 Proje Numaralı "Ilgın (Konya) Yerleşim Alanı Zeminlerinin Jeoteknik Özelliklerinin Araştırılması" projesi tarafından desteklenmiştir. Ayrıca bu çalışmanın deney süreçlerinde, Ankara Üniversitesi YEBİM'in laboratuvarları kullanılmıştır.

\section{Referanslar}

[1] Google Earth Pro Uydu Görüntüsü (Erişim Tarihi: 01.07.2019).

[2] Şengör AMC, Görür N, Şaroğlu F. Strike-Slip Faulting and Related Basin Formation in Zones of Tectonic Escape: Turkey As a Case Study, 1985.

[3] Umut M, Karabıyıkoğlu M, Saraç G, Bulut V, Demirci AR, Erkan M, Kurt Z, Metin S, Özgönül E. Tuzlukçu-Ilgın-Doğanhisar-Doğanbey (Konya İli) ve Dolayının Jeolojik Etüdü Hakkında Rapor, MTA Derleme Rapor Ankara, 1987;No:8246, 51.

[4] Özcan A, Göncüoğlu MC, Turan N, Uysal Ş, Şentürk K, Işık A. Konya-Kadınhanı-Ilgın 
Dolayının Temel Jeolojisi, M.T.A. Genel Müdürlüğü Jeoloji Etütleri Dairesi, Ankara, 1990, Rapor No:9535.

[5] Çağlar AT, Taş N. Konya-Ilgın-Haremiköy ve Kurugöl Çevresinde Yapılan Etüt ve Sondajlı Çalışmalara ait Jeolojik Rapor, Ankara, 1991; 7999, 143.

[6] Eren Y. Ilgın-Sarayönü (Konya) Güneyinde Bozdağlar Masifinin Yapısal Özellikleri, Türkiye Jeoloji Bülteni, 39/2, 49-64,1996.

[7] Hüseyinca MY. Ilgın (Konya) Kuzeyinin Stratigrafisi ve Yapısal Özellikleri, Selçuk Üniversitesi Fen Bilimleri Enstitüsü, Yüksek Lisans Tezi, Konya, 2005.

[8] Özdamar Ş, Esenli F, Uz B. Ilgın (Konya) Kuzeyindeki Metasedimanter ve Metavolkanik Kayaçların Jeolojisi ve Jeokimyası, İ.T.Ü. Dergisi, 2010;Cilt: 9, Sayı: 3, 25-37.

[9] Ozdemir A, Ince I. Geology Seismotectonics and Soil Liquefaction Susceptibility of Ilgin (west-central part of Turkey) Residential Area. Engineering Geol., 2004; 77, 169-188.

[10] Ozdemir A, Nalbantcilar MT. Potential Settlement Due to Seismic Effects in the Residential Area of Ilgin Konya Turkey. Earth Sciences Research Journal, 2016; 20(2), 1-9.

[11] MTA. 1/100000 L27 Paftası Jeoloji Haritası, 2009.

[12] Kandilli Rasathanesi ve Deprem Araştırma Enstitüsü (www.koeri.boun.edu.tr) (Erişim Tarihi: 01.07.2019)

[13] Terzaghi K, Peck BR. Soil Mechanics in Engineering Practice. John Wiley and Sons Inc., 1948;729p. 